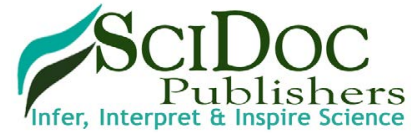

\section{Music Reduces Postoperative Pain Perception in Male Patients after Abdominal Surgery under General Anesthesia}

Research Article

\author{
Varbanova $\mathrm{MR}^{1 *}$, Neamtu $\mathrm{A}^{1}$, Gaar $\mathrm{E}^{2}$, Grigorov $\mathrm{MV}^{4}$ \\ ${ }^{1}$ Assistant Professor Department of Anesthesiology and Perioperative Medicine University of Louisville School of Medicine, USA. \\ ${ }^{2}$ Professor of Surgery University of Louisville School of Medicine, USA. \\ ${ }^{3} 800$ Zorn Ave (112), Louisville, KY 40208, USA.
}

\title{
Abstract
}

Background: Perioperative pain after abdominal surgery is difficult to manage. Despite the advent of multimodal analgesia techniques, the opioids remain the cornerstone of treatment. Since the opioids' adverse effects are of concern immediate postoperatively, music as a modality that would influence human behavior, is of interest as an adjunct for acute pain management. Our hypothesis was that listening to instrumental music during the perioperative period reduces the pain level and decreases the use of opioids within the first 23 hours after the surgery.

Methods: The study was designed as randomized clinical trial, including 54 males who underwent abdominal surgery under general anesthesia. One group was allocated to music therapy intra and postoperatively (G1), and the other was the control group (G2), without music therapy. The statistical analysis for each of the response variable, blood pressure, heart rate, oxygen saturation, visual analogue scale (VAS) score and morphine equivalents (ME), was based on a linear regression analysis accounting for group and time differences and adjusting for covariates (age, height, weight) if necessary (statistically significant).

Results: Our study results show a statistically significant difference regarding the mean VAS measurements between the two groups before and after music therapy on arrival in the Postanesthesia Care Unit (PACU) [2.4; CI 95\% 1.39-3.35 versus 4.1 CI 95\% 2.77-5.53], 30 minutes [ 3 ; CI95\% 2.21-3.87 vs 5.48; CI95\% 4.34-6.62] and 23 hours later [2.15; CI95\% 1.38-2.91 vs 4.37;CI 95\% 3.51-5.24] , respectively (Table 2). There was no statistically significant difference in blood pressure (systolic and diastolic), heart rate, oxygen saturation (SpO2), and opioid consumption between the two groups at the three points in time when measurements were done.

Conclusions: In this study, a short perioperative exposure to music was effective in reducing the pain perception (as measured by VAS method) but not the opioid consumption in the first 23 hours in male patients after abdominal surgery.

Keywords: Music; Perioperative Pain; Pain Perception; Abdominal Surgery; Males.

\section{Introduction}

Music has been used since ancient times for the alleviation of human pain and suffering. The human voice, touch or the sound of music have been historically utilized as additional means of care and comfort.

The use of music during and after surgery has attracted attention again in the last few years $[1,2]$. Although some of the published studies have not fulfilled standard criteria for randomization and control of circumstances, few recent studies point to a direct pain-reducing effect from patient's perioperative exposure to music $[3,4]$.

Music may affect brain functioning in variety of ways: 1) by working on the limbic system regulating centers of emotional responses and 2) by stimulating the release of endorphins thereby alleviating pain $[5,6]$. Alternatively, the beneficial effect may be a result of distraction through cognitive coping strategies by competing stimuli that reduce pain perception [7]. Lately the

\footnotetext{
*Corresponding Author:

Marina Varbanova M.D

Assistant Professor Department of Anesthesiology and Perioperative Medicine University of Louisville School of Medicine, 530 South Jackson Street (C2A01), Louisville KY 40202, USA.

Tel: (502) 2996579 (or) (502) 2876804

E-mail: m0varb01@louisville.edu

marina.varbanova@louisville.edu

Received: May 31, 2016

Accepted: June 24, 2016

Published: June 28, 2016

Citation: Varbanova MR, Neamtu A, Gaar E, Grigorov MV (2016) Music Reduces Postoperative Pain Perception in Male Patients after Abdominal Surgery under General Anesthesia. Int J Anesth Res. 4(6), 272-277. doi: http://dx.doi.org/10.19070/2332-2780-1600058
}

Copyright: Varbanova $\mathbf{M R}^{\circ}$ 2016. This is an open-access article distributed under the terms of the Creative Commons Attribution License, which permits unrestricted use, distribution and reproduction in any medium, provided the original author and source are credited. 
theory of rhythmic entrainment in musical research and music therapy has gained new popularity. Entrainment refers to a process, common for both biological and mechanical systems, by which independent rhythmical systems interact with each other. Rhythmic entrainment in music therapy is a specialized practice used to assist in helping people become more "in tune" to their own rhythm. Most of us are born with the ability to sense rhythm and move to match that rhythm. Our brain hears different tempos and our respiration and circulations respond by matching those tempos [8].

Individuals with acute pain due to diagnostic and therapeutic procedures often suffer from pain despite pharmacologic interventions. Incomplete pain relief postoperatively is estimated to be present in more than half of the surgical patients. It can contribute to changes in sleep pattern, mood, delayed recovery and higher health care costs $[9,10]$.

In 2006, a Cochrane Collaboration systematic review of music for pain relief involving 3663 subjects, found that music decreases pain, increases the number of patients who reported at least $50 \%$ pain relief, and reduced requirements for morphine - like analgesics, but the magnitude of these benefits is small and the clinical importance still to be established [11]. No study has been performed addressing the effect of music on only male patients for abdominal surgery under general anesthesia. Our hypothesis was that listening to instrumental music (piano miniatures) during the immediate perioperative and intraoperative period reduces pain level and decreases the use of opioids within the first 24 hours after the surgery.

\section{Methods}

The study was approved by the Research \& Development Office and the Institutional Review Board of the Robley Rex Veteran Affair Medical Center Louisville Kentucky. 54 subjects participated in the study.

The subjects were selected by pre-screening of the medical records of patients scheduled for abdominal surgery at the Robley Rex VAMC Louisville, KY. Subjects were considered eligible for inclusion in the study if they satisfied the following:

Inclusion criteria: (1) male age between 18 and 75 years and having abdominal surgery; (2) inpatients or at least 23 hour postoperative admit patients; (3) surgery done under general anesthesia; (4) the pain controlled with mainly opioids.

Exclusion criteria: (1) pregnant patients; (2) female patients (3); chronic pain patients; (4) patients above the age of 80 years; (5) patients on scheduled pain medication for period longer of 3 weeks; (6) patients with dementia; (7) patients with regional blocks or neuraxial anesthesia; (8) ASA class 4 and above; (9)patients with hearing impairment (requiring hearing aids); (10) patients with alcohol or drug abuse (11) patients considered incompetent ( requiring consent by a Legal-Authorized Representative).

The selected subjects were asked to sign an informed consent. They were randomized to two groups. Group one (G1), with music treatment (M) and group two (G2), a control group, with no exposure to music (NM). The headphones were placed on each patient at the time of leaving the preoperative area for the operating room. Surgical Serenity Multimedia Headphones Model: HE-ZM5800 with incorporated MP 3 player were used on all study subjects. All patients kept the headphone on, all through the procedure and during they stay in the postoperative care unit until they requested to have the headphones removed or until they were discharged from the postoperative unit.

\section{Study design}

The study was designed as randomized clinical trial. Each day of surgery, an envelope was picked containing the information whether or not music should be used for the particular patient. Computer was responsible for the randomization. The person collecting the data and the one administering the general anesthesia were blinded to which group the particular patient was allocated. The randomization was kept secret until all data were collected. All patients received balanced inhalational general anesthesia for the abdominal surgery.

\section{Sample size calculation}

Based on statistical power analysis, it was estimated that 26 subjects per group are needed in order to detect $20 \mathrm{~mm}$ mean Visual Analogue Scale (VAS) difference with 95\% confidence level and $80 \%$ power. The sample size calculations assumed a typical standard deviation (SD) of $25 \mathrm{~mm}$ which is the median value obtained from a literature search on published SDs of VAS ratings. A total number of 52 subjects, 27 in each group, participated in the study.

\section{Statistical analysis}

The statistical analysis of the response variables was based on a Linear regression analysis accounting for group and time differences and adjusting for covariates (age, height, weight) if necessary (statistically significant). A random effect for each panelist was used to account for correlation between observations from the same subject in the study. Statistical software JMP was used for the analysis. Figure 1 summarizes all models using LMP Profiler.

\section{Intervention and outcome assessment}

Patients randomized to the experimental group (G1) listened to music during surgery via cordless Surgical Serenity Headphones with incorporated MP3 player. The music was preselected and edited by clinical musicologist for its rhythmic properties and consisted of instrumental music (piano miniatures). Prior to surgery, researchers determined the volume level with which each patient was comfortable.

Primary end point was postoperative pain 24 hours after surgery measured using visual analog scale 0-10 (VAS). In addition, pain was estimated at arrival in the postoperative unit (PACU) and at 30 minutes of recovery in PACU.

Secondary end point was the total amount of opioids used for postoperative pain control at arrival in PACU, 30 minutes later and 24 hours postoperatively. The comparison was done in morphine equivalents. 
Figure 1. Prediction Profiler.

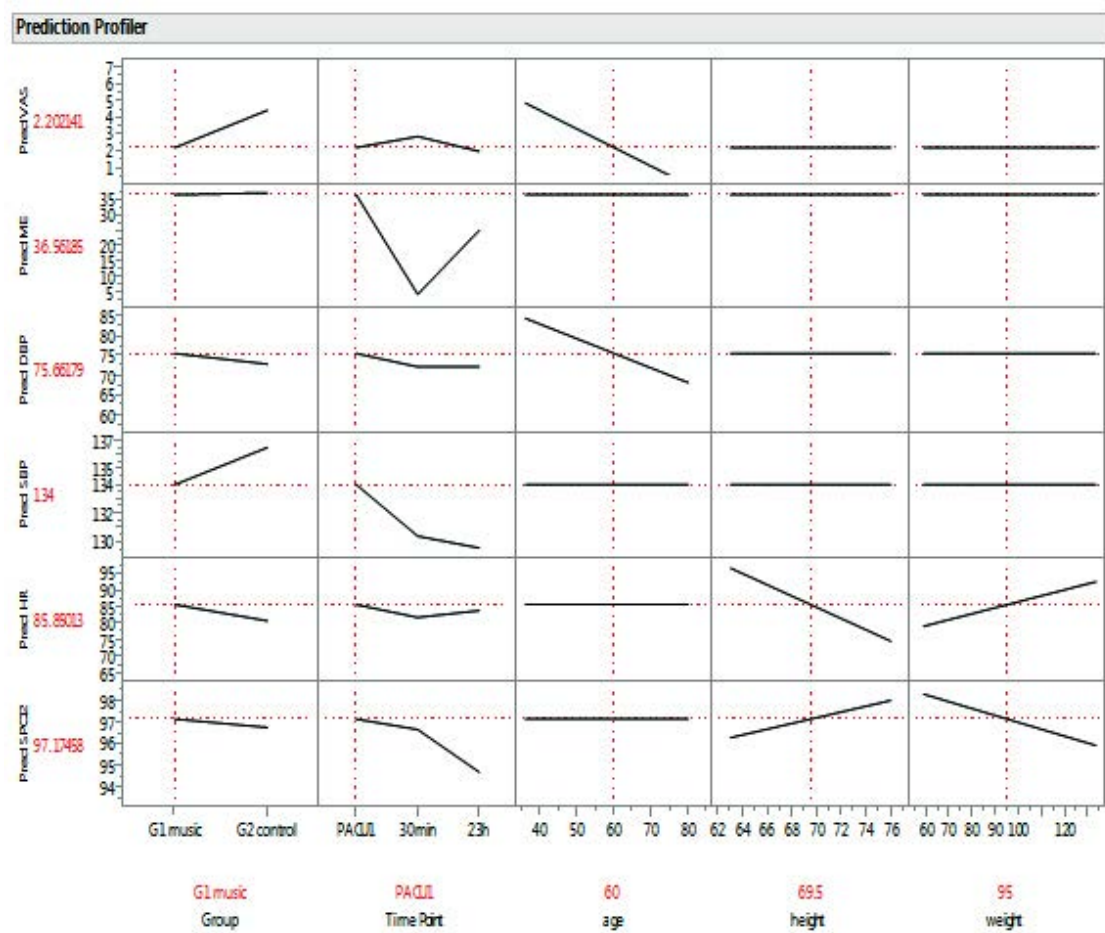

Perioperative data regarding vital signs: blood pressure (SBP and $\mathrm{DBP})$, heart rate (HR), oxygen saturation (SpO2) and morphine equivalents (ME) usage was recorded preoperatively as well at three points of time after the surgery, at arrival in the anesthesia postoperative unit (PACU 1), 30 minutes in recovery room and 24 hours postoperatively.

\section{Results}

Two groups were compared at baseline on 7 characteristics (Table 1). There were not significant group differences across all variables. There is a marginal evidence for some age differences $(\mathrm{P}$-value $=0.06)$ with $\mathrm{G} 2$ control group being about 4 years older on average. The VAS scores at admission were all equal to 0 except for 4 subjects (VAS $=4,5,7,7)$ for $G 1$ Music, and 1 subject (VAS=3) for G2 Control. Based on the comparison of baseline characteristics, there is no evidence to conclude that the two groups were significantly different at the beginning of the study (before treatment).

The statistical analysis for each of the response variable, blood pressure, heart rate, oxygen saturation, VAS score and morphine equivalents (ME), was based on a Linear regression analysis accounting for group and time differences and adjusting for covariates (Age, Height, Weight) if necessary (statistically significant). A random effect for each study subject was used to account for correlation between observations from the same subject in the study. Statistical Software JMP was used for the analysis. Figure 1 summarizes all models using JMP Profiler.

The main findings of our study show a significant difference in the mean VAS scores between the two groups after treatment (2.3 versus 4.9; P-value<0.001). G2 Control group has higher VAS score by 2.6 units compared to G1 Music group. That significant difference is consistent across time points (i.e. no evidence for interaction between group and time point).

The VAS score for both groups were significantly higher at $30 \mathrm{~min}$ by 1 unit versus any of the other two time points $(\mathrm{P}$-value $=0.02)$.

There was a significant age effect on VAS score: Older people tend to have smaller VAS value. Each year increase in age is associated with decrease of 0.11 in the mean VAS score. (See Figure 2)

There are no significant differences between the two groups $(\mathrm{P}$-value $=0.45)$ in morphine equivalents use $(\mathrm{ME})$. There is a significant difference in ME used across time (regardless of group). (see Table 3) The largest amount was intra-operatively assessed at arrival in the postoperative unit, PACU1: 36.9 on average, followed by " $23 \mathrm{~h}$ " (27.8), and " $30 \mathrm{~min}$ " (4.7). None of the Age, Height, or Weight variable was significant in explaining the morphine equivalents (ME) variation, see Figure 3.

There are no significant differences between the two groups in systolic and diastolic blood pressures $(\mathrm{P}$-value $=0.38$ ).

There is a significant difference in DBP across time (regardless of group). The average level for PACU1 (74.1) was significantly higher compared to "30 min" (69.0) but not versus "23h" (72.4).

The heart rate shows no significant differences between groups $(\mathrm{P}$-value $=0.26)$, nor time points $(\mathrm{P}$-value $=0.39)$

There are no significant differences between the two groups $(\mathrm{P}$-value $=0.90)$ in oxygen saturation $(\mathrm{SpO} 2)$. There is a significant difference in $\mathrm{SpO} 2$ across time (regardless of group). The average saturation level on arrival in PACU (97.0) was significantly higher compared to " $23 \mathrm{~h}$ " (95.1) but not versus “30 min" (96.7).

No significant statistical association was found between the following pairs of variables: Morphine equivalents (ME) versus 
Table 1. Baseline Characteristics.

\begin{tabular}{|c|c|c|c|c|}
\hline \multirow{2}{*}{ Variable } & \multicolumn{2}{|c|}{ G1 Music (N=27) } & \multicolumn{2}{c|}{ G2 Control (N=27) } \\
\cline { 2 - 5 } & Mean & $\mathbf{9 5 \%}$ CI & Mean & 95\% CI \\
\hline Age & 58.5 & $(55.5,61.5)$ & 62.6 & $(59.6,65.7)$ \\
\hline Height & 70.4 & $(69.3,71.5)$ & 70.4 & $(69.3,71.5)$ \\
\hline Weight & 94.8 & $(88,101.7)$ & 99.1 & $(92.3,105.9)$ \\
\hline DBP & 78.4 & $(73.7,83.1)$ & 79.0 & $(74.3,83.7)$ \\
\hline HR & 73.3 & $(68.5,78.1)$ & 72.3 & $(67.6,77.1)$ \\
\hline SBP & 131.5 & $(124.8,138.2)$ & 138.6 & $(131.9,145.3)$ \\
\hline SPO2 & 97.0 & $(96.3,97.8)$ & 97.4 & $(96.6,98.2)$ \\
\hline
\end{tabular}

Table 2. VASin group 1 and 2 on arrival in PACU, PACU 30 min and 23 hours postoperatively.

\begin{tabular}{|c|c|c|c|c|c|c|c|}
\hline Time Point & Group & $\mathbf{N}$ & Mean & $\begin{array}{c}\text { Std } \\
\text { Dev }\end{array}$ & $\begin{array}{c}\text { Std Err } \\
\text { Mean }\end{array}$ & Lower 95\% Mean & $\begin{array}{c}\text { Upper 95\% } \\
\text { Mean }\end{array}$ \\
\hline PACU1 & G1 music & 27 & 2.37 & 2.47 & 0.47 & 1.39 & 3.35 \\
\hline PACU1 & G2 control & 27 & 4.15 & 3.48 & 0.67 & 2.77 & 5.53 \\
\hline PACU30min & G1 music & 27 & 3.04 & 2.10 & 0.4 & 2.21 & 3.87 \\
\hline PACU30min & G2 control & 27 & 5.48 & 2.87 & 0.55 & 4.34 & 6.62 \\
\hline 23h & G1 music & 27 & 2.15 & 1.94 & 0.37 & 1.38 & 2.91 \\
\hline 23h & G2 control & 27 & 4.37 & 2.19 & 0.42 & 3.51 & 5.24 \\
\hline
\end{tabular}

Figure 2. Barchart for VAS by Group and Time Point.

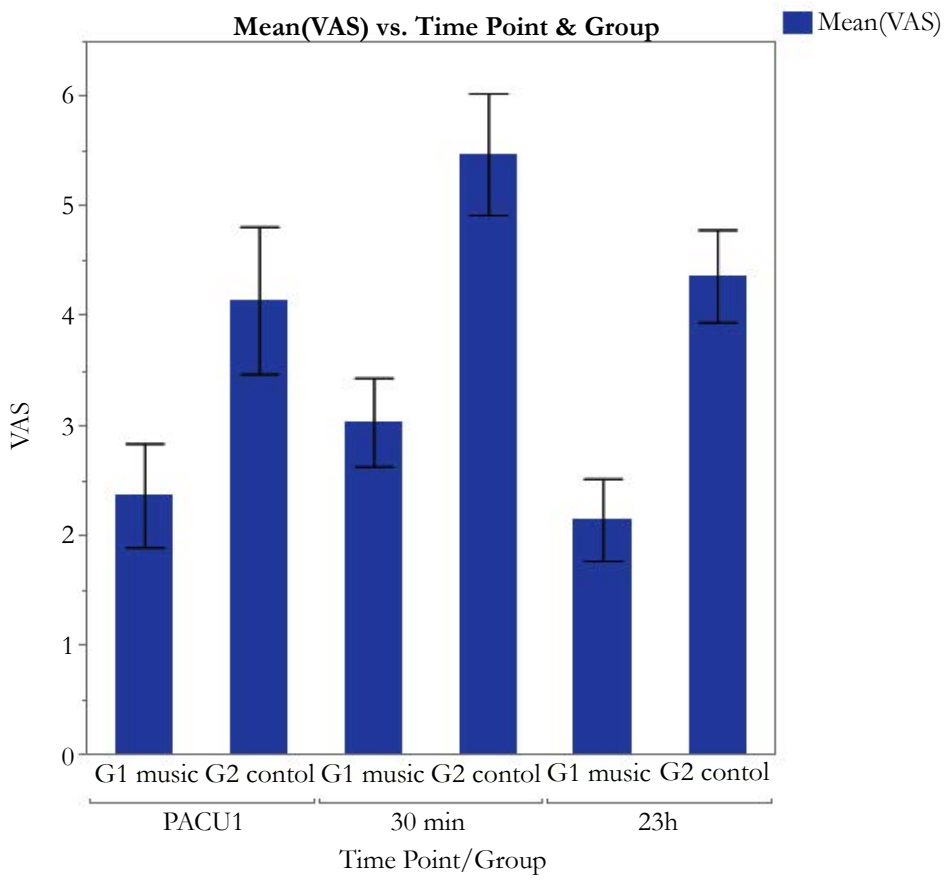

Weight; Group Differences for Morphine Equivalents and Morphine Equivalents (ME) versus SpO2.

\section{Discussion}

The use of music for alleviation of pain has been studied by the medical professionals for years. There is still no consensus whether music should be used preoperatively, intra-operatively or postoperatively. The beneficial effect of music throughout hospital stay was demonstrated previously in women undergoing mastectomy, where music reduced anxiety, mean arterial blood pressure and pain [12]. In our study we were able to show significantly lower VAS score in the exposed to music group compared to the control group, in male patients for abdominal surgery under general anesthesia.

There are conflicting and limited data regarding the role of music on the intraoperative and postoperative analgesic requirements [8]. Music during gynecologic surgery under general anesthesia has been found to decrease intraoperative requirement for analgesia and to produce better pain relief during the first postoperative day [13]. However, music did not reduce intraoperative anesthetic 
Table 3. Systemic opioids administered postoperatively expressed in i.v. morphine equivalents (ME).

\begin{tabular}{|c|c|c|c|c|c|c|c|}
\hline Time Point & Group & $\mathbf{N}$ & Mean & $\begin{array}{c}\text { Std } \\
\text { Dev }\end{array}$ & $\begin{array}{c}\text { Std Err } \\
\text { Mean }\end{array}$ & $\begin{array}{c}\text { Lower 95\% } \\
\text { Mean }\end{array}$ & $\begin{array}{c}\text { Upper } \\
\text { 95\% Mean }\end{array}$ \\
\hline PACU1 & G1 music & 27 & 36.56 & 17.39 & 3.35 & 29.68 & 43.44 \\
\hline PACU1 & G2 control & 27 & 37.2 & 16.41 & 3.16 & 30.71 & 43.70 \\
\hline PACU 30min & G1 music & 27 & 4.57 & 4.39 & 0.84 & 2.83 & 6.30 \\
\hline PACU 30min & G2 control & 27 & 4.85 & 4.38 & 0.84 & 3.12 & 6.58 \\
\hline 23h & G1 music & 27 & 25.18 & 18.42 & 3.54 & 17.89 & 32.47 \\
\hline 23h & G2 control & 27 & 30.36 & 24.48 & 4.71 & 20.68 & 40.04 \\
\hline
\end{tabular}

Figure 3. Bar chart for ME by Group and Time Point.

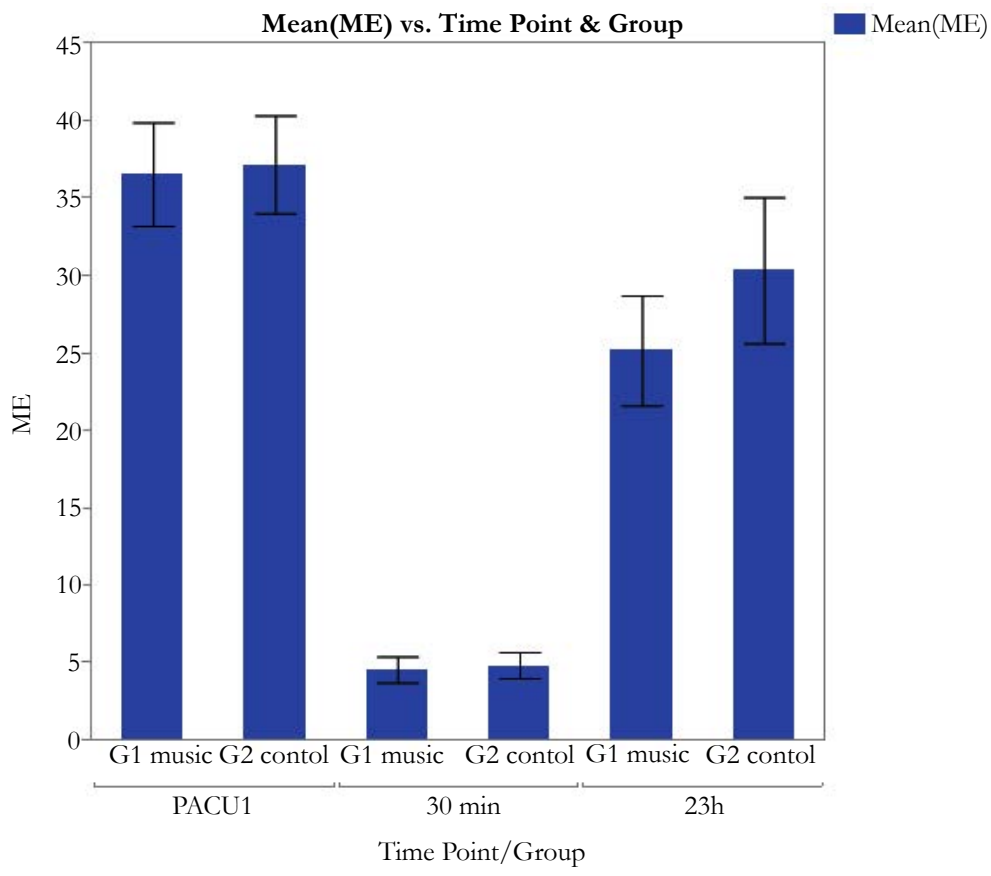

requirements and postoperative analgesic demand during laparoscopic cholecystectomy [14]. In the past, reports about the effect of music on labor pain have been conflicting with some studies demonstrating positive effect of music in decreasing sensation of pain during labor and delivery [15-18], while others noticing no difference in labor pain or analgesic requirements [19, 20].

The effect of music on humans is a matter of ongoing investigation. It is not clear at present how exactly music affects cerebral activity. It is postulated that it involves modulation of neurotransmitters such a dopamine, glutamate and norepinephrine and thus influences mood, emotions and memories [21, 22]. It was found that music influences cerebral plasticity after stroke [23].

Fedorenko et al., by combining individual-subject fMRI analyses with a scrambling method that manipulates musical structure, have provided evidence of brain regions sensitive to musical structure bilaterally in the temporal lobes, they further showed that these regions are sensitive to the scrambling of both pitch and rhythmic structure but are insensitive to high-level linguistic structure. Fedorenko et al, research suggests the existence of brain regions with representations of musical structure that are distinct from high-level linguistic representations and lower-level acoustic representations. These regions provide targets for future research investigating possible neural specialization for music or its associated mental processes [24]. All of it making even more interesting the theory of rhythmic entrainment, its influence onhuman physiology and the use of music as a medium between both. The effectiveness of music during the intraoperative period is unclear. There is some evidence that perioperative use of music may decrease neuroendocrine response to surgery [25].

Our study showed significantly lower VAS score in male patients under general anesthesia for abdominal surgery, exposed intraoperatively to music compared to the control group. We were unable to show statistically significant decrease in the use of opioids in the perioperative period. However, although not statistically significant, the use of morphine equivalents was less in the exposed to music group.

Our study differs from previous ones by the fact that was done only on male patients for abdominal surgery under general anesthesia. The music was preselected classical instrumental, light piano miniatures, administered via cordless headphones with incorporated MP player. None of the patients had a chance to select the type of music. Currently available evidence does not support specific type of music as being more effective or music intervention [26]. To determine if one type of music is better than other types further studies would be required. Our study showed 
a significant difference in morphine equivalents (ME) use across time, but could not reach significant differences in the ME use between the two study groups $(\mathrm{P}$-value $=0.45)$, possibly due to being relatively underpowered. Although our results suggest the possibility of beneficial effects of music on pain perception in male patients after abdominal surgery, future randomized trials are warranted to confirm or refute the hypothesis.

\section{Conclusions}

At the setting of this study, short perioperative and intraoperative exposure to light classical piano miniature music, was effectivein reducing perioperative pain in the first 24 hours in male patients after abdominal surgery. The use of music in the perioperative period is recommended as safe, inexpensive, complementary therapy, in addition to traditional approaches, for alleviating perioperative pain in male patients under general anesthesia.

\section{Acknowledgements \& Declarations}

This article is the result of work supported with resources and the use of facilities at the Robley Rex VAMC Louisville, KY. The content of the current article does not represent the views of the U.S. Department of Veteran Affairs or the United States Government.

\section{References}

[1]. Zhang X, Fan Y, Yuke Tian (2005) Music reduces pain after gynecological surgery with combined spinal epidural anesthesia. Anesthesiology 103: A627.

[2]. Lewis AK, Osborn IP, Roth R (2004) The effect of hemispheric synchronization on intraoperative analgesia. Anesth Analg 98(2): 533-536.

[3]. Nilsson U, Rawal N, Uneståhl LE, Zetterberg C, Unosson M (2001) Improved recovery after music and therapeutic suggestions during general anesthesia: A double-blind randomized controlled trial. Acta Anaesthesiologica Scandinavica 45(7): 812-817.

[4]. Good M, Anderson GC, Stanton-Hicks M, Grass JA, Makii M (2002) Relaxation and music reduce pain after gynecological surgery. Pain Management Nursing 3(2): 61-70.

[5]. Örn P (2000) Biomusikvetenskap - länken mellan music och biologi. Lakartidningen 97(31): 3400-3403.

[6]. Updike PA, Charles DM (1987) Music Rx: Physiological and emotional responses to taped music programs of preoperative patients awaiting plastic surgery. Annals of Plastic Surgery 19(1): 29-33.

[7]. Nilsson U, Rawal N, Enqvist B, Unosson M (2003) Analgesia following music and therapeutic suggestions in the PACU in ambulatory surgery; a randomized controlled trial. Acta Anaesthesiologica Scandinavica 47(3): 278-283.

[8]. Matsota P, Christodoulopoulou T, Smyrnioti ME, Pandazi A, Kanellopoulos I, Koursoumi E ( 2013) Music 's use for anesthesia and analgesia. The Journal of Alternative and Complementary Medicine 19(4): 298-307.

[9]. Good M, Albert JM, Anderson GC, Wotman S, Cong X, Lane D (2010) Supplementing relaxation and music for pain after surgery. Nursing Research 59(4): 259-268.

[10]. Ikonomidou E, Rehnström A, Naesh O (2004) Effect of music on vital signs and postoperative pain. AORN Journal 80(2): 269-278.

[11]. Cepeda MS, Carr DB, Lau J, Alvarez H (2006) Music for pain relief. Cochrane Database of Syst Rev 19(2): CD004843.

[12]. Binns-Turner PG, Wilson LL, Pryor ER, Boyd GL, Prickett CA (2011) Perioperative music and its effects on anxiety, hemodynamics, and pain in women undergoing mastectomy. AANA J 79(4 Suppl.): 21-27.

[13]. Nilsson U, Rawal N, Uneståhl LE, Zetterberg C, Unosson M (2001) Improved recovery after music and therapeutic suggestions during general anesthesia: A double-blind randomized controlled trial. Acta Anaesthesiol Scand 45(7): 812-817.

[14]. Szmuk P, Aroyo N, Ezri T, Muzikant G, Weisenberg M, Sessler DI (2008) Listening to music during anesthesia does not reduce the sevoflurane concentration needed to maintain a constant bispectral index. Anesth Analg 107(1): 77-80.

[15]. Clark ME, McCorkle RR, Williams SB (1981) Music therapy assisted labor and delivery.J Music Ther 18(2): 88-100.

[16]. Halpaap B, Spintge R, Droh R, Kummert W, Kögel W (1987) Anxiolytic music in obstetrics: Music in Medicine. Springer-Verlag, Berlin,NewYork. 232-242.

[17]. Browning CA (2000) Using music during childbirth. Birth 27(4): 272-276.

[18]. Phoumdoung S, Good M (2003) Music reduces sensation and distress of labor pain. Pain Manage Nurs 4(2): 54-61.

[19]. Durham I.,Collins M (1986) The effect of music as a conditioning aid in prepared childbirth education. J Obstet Gynecol Neonatal Nurs 15(3): 268270.

[20]. Kusolleartjariya S (1997) A study of comparison between folk's music and classical music to decrease labor pain. Thai J of Health Promot and Environ Health 20: 32-42.

[21]. SàrkàmoT,Soto D (2012) Music listening after stroke: beneficial effects and potential neural mechanisms. Ann NY Acad Sci 1252: 266-281.

[22]. Cooke M, Chaboyer W, Hiratos M (2005) Music and its effect on anxiety in short waiting periods:a critical appraisal. J Clin Nurs 14(2): 145-155.

[23]. Särkämö T, Pihko E, Laitinen S, Forsblom A, Soinila S, Mikkonen M, et al., (2010) Music and speech listening enhances recovery of early sensory processing after stroke. J Cogn Neurosci 22(12): 2716-2727.

[24]. Fedorenko E, McDermott JH, Norman-Haignere S, Kanwisher N (2012) Sensitivity to musical structure in the human brain. J Neurophysiol 108(12): 3289-3300.

[25]. Chanda ML, Levitin D (2013) The neurochemistry of music. Trends in Cognitive Sciences 17(4): 179-193.

[26]. Evans D (2002) The effectiveness of music as an intervention for hospital patients; a systematic review. Journal of Advanced Nursing 37(1): 8-18. 